\title{
Preliminary Conception of Financial Decision Knowledge Engineering
}

\author{
Linhui Qiu ${ }^{1, *}$ \\ ${ }^{1}$ Business Administration, Wuhan University Of Technology, Wuhan, Hubei, 430070, China
}

\begin{abstract}
In the era of digital economy, the intelligence of enterprise financial management has an important influence on the effect of enterprise financial activities. At present, the application of intelligent financial system and software focuses on providing analysis information for financial decision-making, and cannot effectively give complete financial decision-making suggestions, nor does it combine with enterprise strategy. This paper puts forward the idea of constructing knowledge engineering of financial decisionmaking based on frame, and uses frame representation to express the knowledge of financial decisionmaking and enterprise strategy, so as to promote the combination of intelligent financial decision-making and enterprise strategy, and promote the intelligence of enterprise financial decision-making through knowledge engineering.
\end{abstract}

\section{Introduction}

In the era of digital economy, the digitalization and intellectualization of enterprise financial management have an important influence on the efficiency and effect of enterprise financial activities. At present, the application of intelligent financial system and software focuses on the efficient identification and extraction of business information[1], data processing and statistical analysis, the formation of financial statements, internal control[2], business diagnosis and risk early warning, etc. A few software such as yonyou and Kingdee provide decision support system services, but they only provide reference information for financial decision-making, and couldn't effectively provide direct and complete decision-making suggestions. And they're limited to financial management and can not be combined with enterprise strategy. Therefore, this paper puts forward the idea of applying knowledge engineering to financial decision-making, constructs financial decision-making knowledge engineering based on framework, and uses framework representation to express financial decisionmaking knowledge and enterprise strategy knowledge, hoping to promote the development of intelligent financial decision-making combined with enterprise strategy.

\section{Overview of financial decision making}

\subsection{Overview of financial decision making}

Financial decision-making is the decision-making of all financial activities such as short-term financial strategies and financial plans of an enterprise. Scientific financial decision-making can make business activities more scientific and planned, allocate resources reasonably, improve profitability and reduce profit loss caused by blind operation. Financial decision-making has an important impact on the implementation of the overall strategy of enterprises and the regulation of business risks. It also affects and restricts the activities of purchasing, production, marketing, human resources and other functions of enterprises.

\subsection{The importance of the combination of financial decision and strategy}

Enterprise strategic management is a dynamic process of establishing enterprise mission, setting enterprise organizational goals according to the external environment and internal business elements of the enterprise, ensuring the correct implementation of the goals and finally realizing the enterprise mission[3]. The overall strategy of an enterprise is a long-term and overall plan for its operation and a guide for the whole process of its operation. The financial decision-making of an enterprise is influenced by financial status, overall strategy and other factors, as shown in the figure below: 


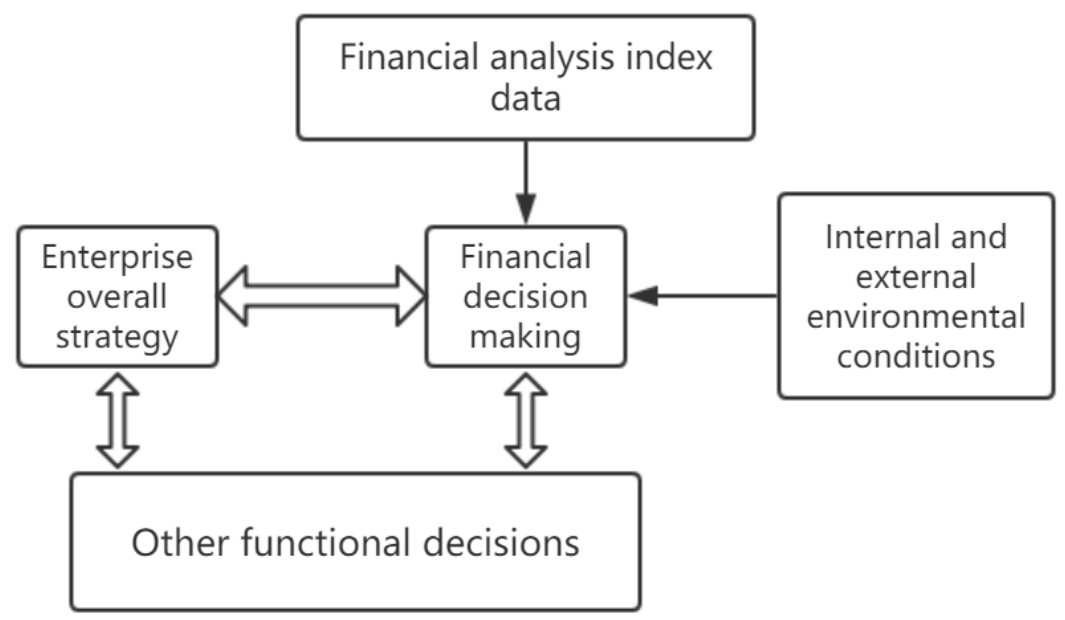

Figure 1. The main influencing factors of financial decision

Therefore, the financial decision-making of an enterprise should not be limited to the internal financial functions. It should be planned around the overall strategy of the enterprise, and coordinated with other functional strategies such as purchasing, production, marketing and human resources.

\section{3 the idea of building financial decision knowledge engineering based on framework}

This paper will start from the needs of financial decisionmaking and put forward the idea of building financial decision knowledge engineering based on framework.

\subsection{Construction of knowledge base combined with enterprise strategy}

In terms of the source of knowledge acquisition, the knowledge of financial decision-making knowledge engineering is mainly expert knowledge, and the financial experts who participate in the construction cooperate with the engineering personnel to sort out the relevant knowledge into computer language to form knowledge bases.

Frame representation is used to represent financial decision knowledge. Taking the selection of evaluation index for project investment decision as an example, when an enterprise wants to make investment decision for a project, it needs to consider Payback period (PBP), Net Present Value (NPV), Present Value Index (PVI), Internal Rate of Return (IRR) and other indexes, and may focus on one of the indicators as needed. In this regard, we could build frameworks like these:

Table 1. Examples of investment decision evaluation index.

\begin{tabular}{l|l|l|l}
\hline FRAME & SLOT & FACET & FACET VALUE \\
\hline PBP & ISA & Numerical value & \\
& AKO & Evaluation index of investment decision & \\
& Premise & The hanging speed of competitive environment & Fast \\
& Aim & Numerical value & Quick recovery of investment \\
\hline IRR & AKO & Evaluation index of investment decision & \\
& Premise & Aim & High return \\
\hline
\end{tabular}

As shown in the table above, PBP is mainly used to evaluate projects that must be recovered as soon as possible, or to make investment decisions when the enterprise is in the market environment of rapid product upgrading and fierce competition, and it is difficult to predict the future cash flow. IRR is suitable for largescale investment projects that pursue higher real rate of return [5]. When users input the requirements of enterprise strategy, such as pursuing high returns or quickly recovering investment amount, the system will 
select the appropriate evaluation index to evaluate the project and decide whether to invest or not.

\subsection{Human-computer interaction in knowledge engineering of financial decision}

After all the information of enterprise financial index data, enterprise strategy, internal environment, external environment and so on, which are involved in a large number of typical financial decision-making cases provided by experts, are constructed into the framework, when users use the financial decision knowledge engineering to make decisions, they only need to input the corresponding constraints, such as enterprise strategic objectives, external environment and so on, the system can automatically analyze and make decisions according to the limited conditions. And the financial data is directly from the enterprise's original online financial system. In decision-making practice, if the financial personnel are not satisfied with the decision-making suggestions given by the system, they can adjust and replace the reasoning logic selected in the system, or modify the limiting conditions to make the system re reasoning.

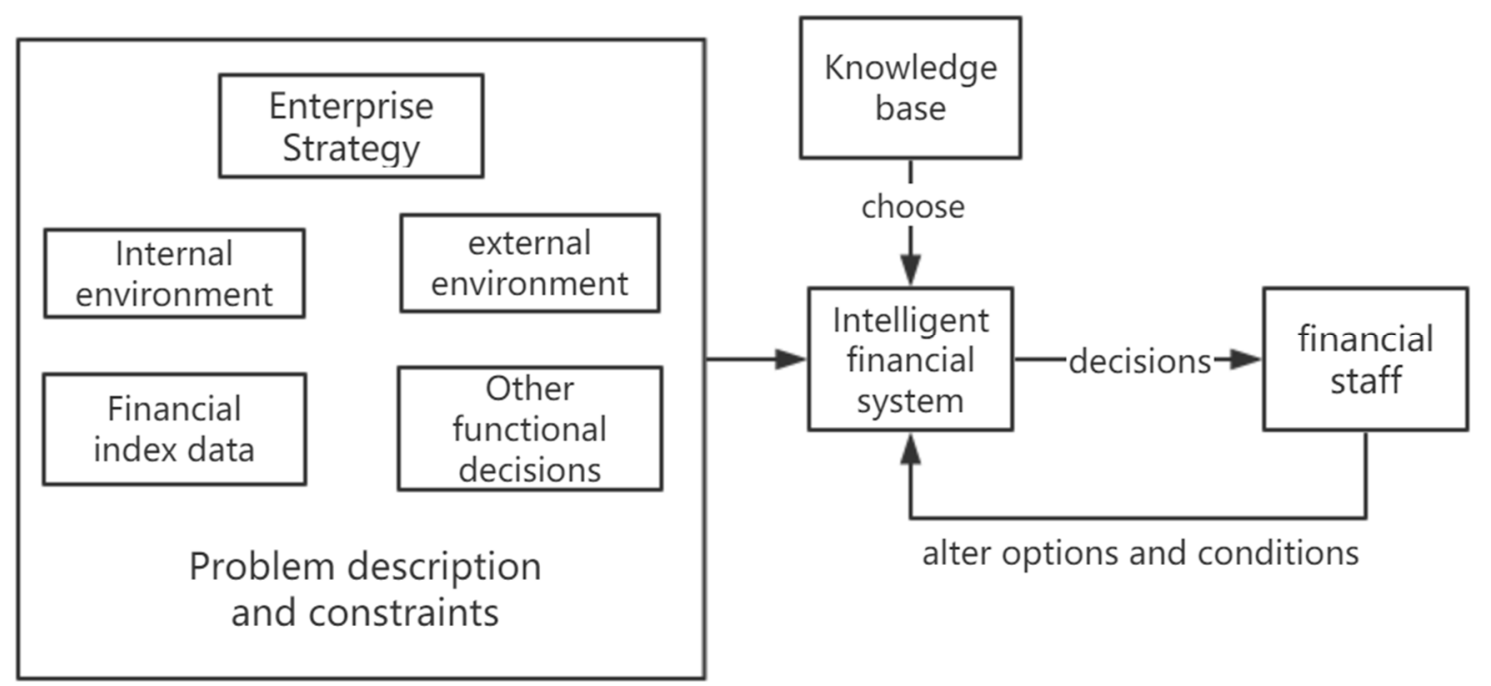

Figure 2. Human-computer interaction in knowledge engineering of financial decision

\section{The significance of constructing financial decision knowledge engineering}

\subsection{The function of constructing financial decision knowledge engineering}

\subsubsection{Improve the level of financial decision-making, make up for the shortcomings of decision-makers}

Knowledge engineering is a typical representative of semiotics artificial intelligence. Semiotics believe that artificial intelligence originates from mathematical logic, and that the essence of intelligence is symbolic operation and operation[4], which is suitable for financial decision- making that requires rigorous and careful logical process. The application of knowledge engineering to financial decision-making is expected to enable intelligent financial system to have the ability to make decisionmaking suggestions, which can promote the initial transformation of financial decision-making from human decision-making to intelligent application decisionmaking. That is to say, financial decision-making will change from the financial personnel using intelligent financial system to improve work efficiency and assist their own decision-making to making decisions automatically through intelligent financial system. This change will help to improve the efficiency and level of financial decision-making, and make up for the lack of knowledge, experience and ability of decision-makers. 


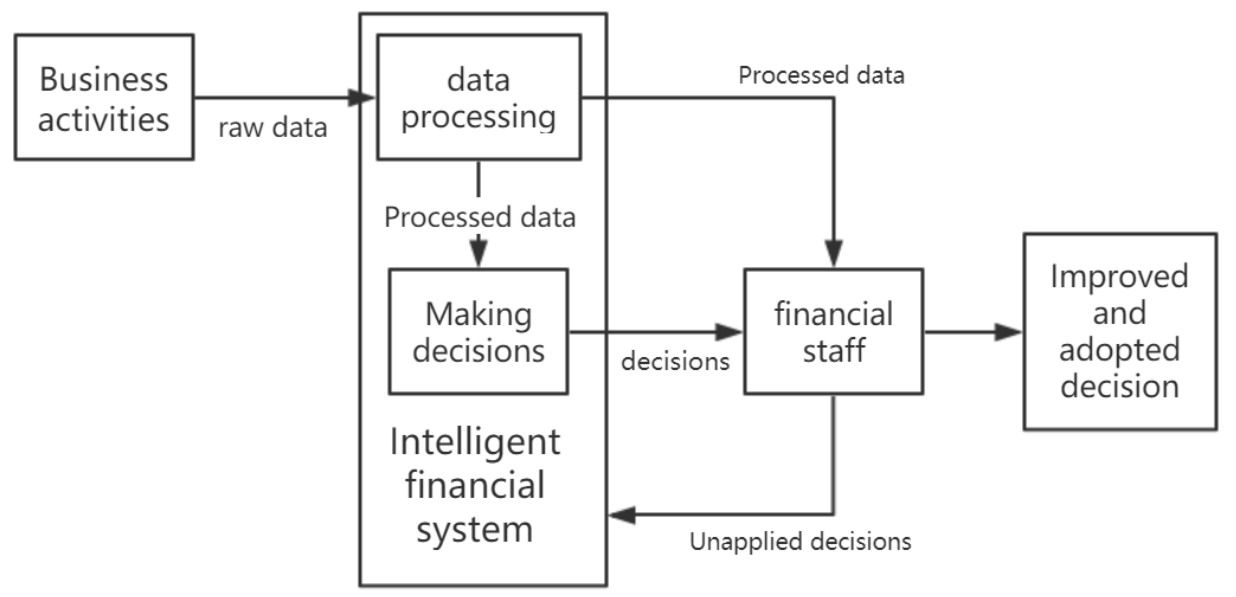

Figure 3. The financial decision-making process of knowledge engineering is applied

\subsubsection{Promote the combination of financial decision and enterprise strategy}

Through rational use of frame representation, it can not only include the knowledge of financial internal decision-making, but also include the knowledge of enterprise strategy, and realize the combination of financial decision-making and strategy. At the same time, this knowledge engineering can also lay a foundation for the intelligent transformation of other functional departments of the enterprise.

\subsection{The favorable external opportunity of building financial decision knowledge engineering}

The construction of knowledge engineering needs a lot of human, material, financial and time investment. Now, cloud computing enables enterprises to use external information technology resources to process their own data without having to build or purchase a complete intelligent software system. The construction of financial decision-making knowledge engineering can be completed by a professional third-party organization, which is more professional and efficient. Financial decision-making knowledge engineering has become a part of its intelligent financial system. Third party organizations provide online intelligent financial analysis and decision-making services to a large number of enterprises through cloud computing technology. Enterprises only need to buy part of the services they need. This is an economical and efficient way for thirdparty organizations and enterprises. In this context, there will be more third-party institutions to invest resources in the construction of financial decision-making knowledge engineering, to promote the development of knowledge engineering research.

\section{5 summary}

In the digital era, financial decision-making knowledge engineering is of great significance to the intelligent financial management of modern enterprises. It can provide the efficiency and level of financial decisionmaking, and make up for the lack of knowledge, experience and ability of decision-makers. From the perspective of the actual needs of financial decisionmaking, this paper puts forward the preliminary idea of building a framework based financial decision-making knowledge engineering, and proposes to use the framework representation method to express the financial decision-making knowledge and enterprise strategic knowledge, so as to promote the combination of intelligent financial decision-making and enterprise strategy, and promote the intellectualization of enterprise financial decision-making through knowledge engineering. From the perspective of enterprise needs, in the future, knowledge engineering will play an increasingly important role in the combination of enterprise functional department decision-making and enterprise strategy.

\section{References}

1. He Y., Li L.S., Yu W.L. (2020) Research on intelligent accounting engine based on machine learning. J. Friends of accounting, 5: 52-58.

2. Sun H.M., Lei Y.J. (2019) Exploration of internal control risk and prevention under the environment of big data and artificial intelligence. J. Friends of accounting, 13: 118-122.

3. Wang F.H., Lv W. ( 1997 ) Enterprise strategic management. Fudan University Press, Shanghai:.

4. Cao Y. (2019) From knowledge engineering to knowledge mapping. https://swarma.org/?p=15537

5. Wen S.B., Liu B., (2016) Management accounting tools and application cases -- evaluation tools and application of project investment decision. J. Friends of accounting,21:134-136. 